\title{
The role of perforating artery pedicled neurotrophic flap in the treatment of compound tissue defect of tibia with llizarov technique
}

\section{Yu-bo Zhang}

Shanghai Sixth Peoples Hospital

\section{Yuan-jian Wu}

Shanghai Zhujiajiao People's Hospital

\section{Wen-jun Zhang}

Shanghai Zhujiajiao People's Hospital

\section{Tao Zhang}

Shanghai Zhujiajiao People's Hospital

Tengfei Lou ( $\sim 1522675605 @ q q . c o m$ )

Shanghai Sixth Peoples Hospital

\section{Pei Han}

Shanghai Sixth Peoples Hospital

\section{Research article}

Keywords: Pedicled flap, Ilizarov technique, Compound defect, reconstruction

Posted Date: December 2nd, 2020

DOI: https://doi.org/10.21203/rs.3.rs-56741/v2

License: (c) (1) This work is licensed under a Creative Commons Attribution 4.0 International License. Read Full License 


\section{Abstract}

Background The aim of this research is to present our experience with the combined use of pedicled neurotrophic flap and distraction osteogenesis in management of complex lower extremity injuries with composite bone and soft tissue defects and assess the functional and cosmetic results of this method.

Methods Between 2008 and 2016, soft tissue coverage with pedicled neurotrophic flap followed by distraction osteogenesis using llizarov external fixator was performed in 25 patients for reconstruction of segmental bone defects of lower extremity complicated by massive loss of soft tissue. There were 16 men and 9 women: their mean age was 39 years ( 23 to 57 ) at the time of surgery. The soft tissue defect after radical debridement ranged from $5 \times 9 \mathrm{~cm}^{2}$ to $11 \times 14 \mathrm{~cm}^{2}$, and the average size of segmental defect was $5.02(2.5$ to 7.5$) \mathrm{cm}$.

Results The distally based sural neurovascular flap was performed in 13 patients, and the greater saphenous neurocutaneous perforator flap in 12 patients. All flaps survived completely without complications. The bone defects were corrected by a mean lengthening of $6.74(4.5$ to 9.5$) \mathrm{cm}$. The function was judged to be excellent in 12 patients and good in 13 patients. Bone results were graded as excellent in 18 patients and good in 7 patients. Complications observed in the process of the treatment included pain, pin tract infections (PTI), ankle midfoot joints stiffness, and nonunion of docking sites. All the cases achieved successful limb salvage and satisfactory function recovery without recurrence of infection.

Conclusions The combined technique of a perforator artery pedicled neurotrophic flap and distraction osteogenesis should be considered to be an effective alternative approach in the salvage treatment of the massively traumatized and chronically infected lower extremity.

\section{Background}

High-energy lower extremity fractures with massive soft-tissue and bone defect remains a considerable challenge for both orthopaedic and reconstructive plastic surgeons. These injuries are typically classified as Gustilo type III and are commonly related to significant morbidity caused by concomitant vascular and soft-tissue injury [1,2]. The purpose of limb-salvage treatment of these patients is restoration of limb function. However, the process can be lengthy and accompanied with risks of infection, deformity, joint contractures, limb length discrepancy, and even amputation [3].

With the development of microsurgical techniques in recent years, skin flap transplantation has become routine practice enabling massive soft tissue defects of the lower extremity to be reconstructed $[4,5]$. Francel and Yaremchuck have demonstrated that management of Gustilo III fractures with radical debridement, skin flap transfer, external fixation and bone grafting may significantly improve the rate of limb salvage [6]. However, the incidence of impaired function of the treated limb, which was caused by nonunion, bony malunion, limb length discrepancy, and angulation deformities, was still high in those patients. 
The technique of distraction osteogenesis can not only reconstruct the segmental defect but also address the coexisting troubles of limb discrepancy, deformity, and joint contractures [7-9]. It is also reported that this technique can repair a combined soft tissue defect in a one stage procedure [10]. However, this only can be accomplished under the condition that the defect of the soft tissue is smaller than that of the bone.

Therefore, the combination of the two potent approaches of Ilizarov technique and free tissue transfer for limb salvage is expected to merge the advantages of both sides, which may lead to an improved functional outcome in patients suffering from Gustilo type III fractures.

The aim of this research is to illustrate our experience with the united use of pedicled neurotrophic flap and distraction osteogenesis in management of complex lower extremity injuries with composite bone and soft tissue defects and assess the functional and cosmetic results of this method.

\section{Methods}

\section{Patients}

This study was reviewed and approved by our institutional review board, and informed consent was obtained from all patients. The combined surgical technique of pedicled neurotrophic flap and distraction osteogenesis was applied to 25 patients with high-energy tibial fractures between May 2010 and August 2016 at our hospital, and all elected for this management as an alternative to amputation. The patients were composed of 16 males and 9 females with an average age of 47 (22 to 67) years at the time of surgery (Table 1). All the cases were initially Gustilo-Anderson grade IIIB open fractures. Patients who underwent femoral transport, did not consent to this study, or were younger than 18 years were excluded from the study. The average time from injury to initial surgery at our institution was 9.32 (1 to 20) weeks. The soft tissue defect after radical debridement ranged from $5 \times 9 \mathrm{~cm}^{2}$ to $11 \times 14 \mathrm{~cm}^{2}$, and the average size of segmental defect was $5.02(2.5$ to 7.5$) \mathrm{cm}$. Seventeen of these patients had a history of local infection, which was diagnosed through bacterial culture of pathogenic tissue biopsy. The details of the patients including the organisms in those with an infection, and the previous operations, are shown in Table 1.

\section{Surgical Technique}

X-ray radiography, computed tomography $(\mathrm{CT})$, or positron emission tomography-CT (PET-CT) were performed to preoperatively assess the possible extent of the infected or dead tissues. Limb discrepancy and mechanical axis deviation were evaluated by long-leg radiographs. Active infection was detected with laboratory examinations including full blood count, C-reactive protein (CRP), and erythrocyte sedimentation rate (ESR).

Any remaining metal implants from previous surgeries were removed. A temporary external fixator followed by aggressive debridement of necrotic or infected soft tissue and bone (Fig. 1a) was carried out 
before the application of flap coverage.

When the wound was considered clean囚pedicled flaps with a marked perforator artery were performed for soft tissue coverage. The choice of flap depended mainly on the defect size and location, and the required pedicle length. The distally based sural neurovascular fasciocutaneous flap, providing a long pedicle and being nourished by the sural nerve and the peroneal artery, was designed to repair the soft tissue defects of lower leg and the ankle. In addition, the greater saphenous neurocutaneous perforator flap, yielding a relatively short pedicle and being nourished by greater saphenous vein and the saphenous nerve, was performed to cover defects located on medial and anterior aspects of the injured extremity. The color and temperature of the flaps were monitored in order to predict perfusion and venous conditions.

After the flap has healed and the edema subsided, normally four to six weeks subsequent to the soft tissue reconstruction, an llizarov circular or unilateral frame was used in place of the temporary external fixator. However, in six of our cases we performed the replacement of external fixator immediately after flap coverage on account of the relatively superior soft tissue conditions.

\section{Postoperative Care}

Prophylactic antibiotic was administrated intravenously for one to two weeks after operation to prevent infection. The selection of antibiotics is targeted according to the results of previous bacterial culture. Distraction rate of $4 \times 0.25 \mathrm{~mm}$ per day was commenced following a latency period of 5 to 7 days. The compression of the docked ends continued for 5 days after the achievement of docking to get full contact. Moderate range of motion training of knee and ankle joint was started on the second day postoperatively. Gradual partial weight-bearing was encouraged during the process, and full weight bearing exercise was permitted when docking was completed. A clinical and radiographic examination was performed once two weeks during the distraction phase, and once a month during the consolidation phase. Consolidation was considered satisfactory when the formation of a bridging callus was visible on at least three cortices in the anteroposterior and lateral radiographs. If there were no signs of clinical and radiographical union within three months after the bone contact having been completed, bone grafting, resection of atrophic bone ends, or plate fixation replacement were carried out. The results of bone and function was evaluated by two independent evaluators with the criteria reported by Paley (Table 2).

\section{Results}

Twenty-five patients were followed up for an average of 28.96 (15 to 48) months. The distally based sural neurovascular flap was performed in 13 patients, and the greater saphenous neurocutaneous perforator flap in 12 patients. The flap area ranged from $5 \times 10 \mathrm{~cm}$ to $12 \times 14 \mathrm{~cm}$. Sufficient coverage of soft tissue defect was achieved in all cases. All flaps survived completely without complications. The bone defects were remedied by an average lengthening of $6.74(4.5$ to 9.5$) \mathrm{cm}$. The residual discrepancy was $<1 \mathrm{~cm}$ in all cases, which was not clinically significant. No recurrence of infection was found in infected patients. 
According to the criteria reported by Paley, bone results were judged excellent in 18 cases and good in the rest 7 cases, functional results were graded as excellent in 12 patients and good in 13 (Table 3).

Pain was the most frequent complaint that we encountered in the course of treatment. In most cases, the patients felt relieved by using oral analgesics. While two patients who found the pain was intolerable were treated effectively with decreasing the lengthening rate. Pin tract infection graded as II (inflamed) and III (inflamed with serous discharge) based on Dahl's classification were found in 6 patients [11]. They responded well to frequent dressing changes and oral antibiotic treatment. Infection of grade $\mathrm{V}$ (inflamed with osteolysis) occurred in one patient who was successfully treated by pin extraction. Six patients developed mild ankle midfoot joints stiffness, which improved after physiotherapy. The docking sites failed to achieve bony union in 5 patients. 12 of them were treated with resection of atrophic bone ends and bone grafting, while 6 of them were treated with plate fixation.

\section{Discussion}

The technique of distraction osteogenesis put forward by llizarov is a biological method to reconstruct segmental defects and has been universally performed for the management of non-union, osteomyelitis, deformity, traumatic bone loss, and leg-length discrepancy.

Both microvascular and local flaps can offer soft tissue envelope, increase blood supply, improve bone healing, and defend against infection [12]. According to the basic surgical principles for the management of Gustilo III open fractures, early soft tissue coverage has been proven crucial and effective during the treatment $[4-6,10]$.

Theoretically, combination of these two powerful techniques could probably be an ideal method for reconstruction of segmental bone defects complicated by massive loss of soft tissue. We carried out the combined surgical technique of artery pedicled neurotrophic flap and distraction osteogenesis to treat 25 patients with high-energy tibial fractures graded as Gustilo III. All the cases achieved successful limb salvage and satisfactory function recovery without recurrence of infection.

The united of free tissue transfer and distraction osteogenesis has also been reported as an effective method for limb salvage in composite injuries [5,12]. However, the drawbacks of this technique including long operation time, donor site morbidity, and high technical requirement should not be ignored. Also, distraction osteogenesis beneath a free flap would compromise the vascularized tissue $[13,14]$. Therefore, instead of a free flap, we performed perforator artery pedicled neurotrophic flap, which is simpler and more efficient, for covering massive soft tissue defects. In this study, all flaps survived completely without complications. In addition, the concern of jeopardy to the pedicle resulting from device placement or subsequent distraction was not observed in this study. We attribute this to careful planning, small diameter of the wires, good stabilization of the flap, tolerable distraction rate, and the technique of percutaneous placement. 
Unlike other surgeons $[15,16]$, we did not perform temporary acute shortening and subsequent distraction in any of our patients. Because this technique causes limb disfigurement and may also leads to twist of the vasculature, which may further jeopardize the circulation of the mangled fractured extremity.

In spite of the surgical technique we presented in this study, single-stage reconstruction with an osteocutaneous flap is also an alternative to treat such complicated injuries [12,17]. This technique immediately fills bone defect, provides soft tissue coverage, and establishes vascularity to the bony bed. However, there are several factors which hinder the technique to be popular in clinic. The bone grafts usually cannot match in in caliber with tibia, which makes a long non-weight-bearing period inevitable to achieve compensatory hypertrophy. On the other hand, performing a single operation to address the softtissue and bone defect using a single large composite flap or multiple free flaps was not advisable due to the high risk of infection in infected cases. Also, this process is associated with a high risk of refracture or nonunion and has an unpredictable outcome. Our staged approach offers a number of benefits over single-stage reconstruction. Firstly, we would wait at least 4 weeks after debridement and soft-tissue coverage before carrying out the llizarov technique of distraction osteogenesis, during which any residual infection may manifest itself before bone reconstruction. Secondly, it can be used in reconstructing defects of any length and diameter without the need for a bone bank or the risks of donor site morbidity. Thirdly, the quality of bone obtained by distraction osteogenesis is better than that in vascularized fibular.

However, disadvantages of this combined technique including cost of treatment, complexity of added surgery, requirement of multiple outpatient adjustments, and long duration of treatment should be considered. The shortcomings of this study are the small number of enrolled cases, the lack of control group, and the short-term following up. Another limitation is that the cohort of patients is very heteronomous when compared the time from injury to initial surgery due to the fact that patients were commonly not sent to our hospital immediately.

\section{Conclusion}

The combined technique of a perforator artery pedicled neurotrophic flap and distraction osteogenesis should be considered to be an effective alternative approach in the salvage treatment of the massively traumatized and chronically infected lower extremity.

\section{Abbreviations}

PTI, pin tract infection; CT, computed tomography; PET-CT, positron emission tomography-CT; CRP, Creactive protein; $E S R$, erythrocyte sedimentation rate;

\section{Declarations}

Ethics Approval[This study are approved by the Ethics Committee of Shanghai Jiao Tong University Affiliated Sixth People's Hospital. Informed consent for participation was obtained from all participants in 
this study.

Consent for publication: All consents to publish from the patients who took part in this study were obtained.

Availability of data and materials: The datasets used and analyzed during the current study are available from the corresponding author on reasonable request.

Competing Interests: The authors declare that they have no conflict of interest.

Funding: There is no funding source.

\section{Author's contributions:}

YW: Designing the study, analyzing and interpreting the data, drafting the manuscript.

YB: Designing the study, analyzing and interpreting the data, drafting the manuscript.

WZ and TZ: Supervising the project and reviewing the manuscript.

$\mathrm{PH}$ : Acquiring the data, critically revising the manuscript.

TL: Designing the study, acquiring the data, critically revising the manuscript.

All authors read and approved the final manuscript.

Acknowledgements: We are thankful for the support of the nursing staff from the Orthopaedic Department, Shanghai Jiao Tong University Affiliated Sixth People's Hospital.

\section{References}

1. Gustilo RB, Anderson JT. Prevention of infection in the treatment of one thousand and twenty-five open fractures of long bones: retrospective and prospective analyses. J Bone Joint Surg Am, 2000;58(4):453-458.

2. Gustilo RB, Mendoza RM, Williams DN. Problems in the management of type III (severe) open fractures: a new classification of type III open fractures. J Trauma, 1984;24(8):742-746.

3. Saddawi-Konefka D, Kim HM, Chung KC. A systematic review of outcomes and complications of reconstruction and amputation for type IIIB and IIIC fractures of the tibia. Plast Reconstr Surg, 2008;122(6):1796-1805.

4. Wang CY, Chai YM, Wen G, Han P. One-stage reconstruction of composite extremity defects with a sural neurocutaneous flap and a vascularized fibular graft: a novel chimeric flap based on the peroneal artery. Plast Reconstr Surg, 2013;132(3):428e-437e. 
5. Lowenberg DW, Feibel RJ, Louie KW, Eshima I, Combined muscle flap and Ilizarov reconstruction for bone and soft tissue defects. Clin Orthop Relat Res. 1996,(332):37-51.

6. Francel TJ, Vander Kolk CA, Hoopes JE, Manson PN, Yaremchuk MJ, Microvascular soft-tissue transplantation for reconstruction of acute open tibial fractures: timing of coverage and long-term functional results. Plast Reconstr Surg. 1992;89(3):478-487; discussion 488-479.

7. Lou TF, Hamushan M, Li H, Wang CY, Chai Y, Han P. Staged distraction osteogenesis followed by arthrodesis using internal fixation as a form of surgical treatment for complex conditions of the ankle. Bone Joint J, 2018;100-B(6):755-760.

8. Lou TF, Li H, Chai YM, et al.Resection arthrodesis using distraction osteogenesis then plating as a hybrid surgical technique for the management of bone sarcomas of the distal tibia. Int Orthop. 2018;42(3):705-711.

9. Lou TF, Wen G, Wang CY, Chai YM, Han P, Yin XF. L-shaped corticotomy with bone flap sliding in the management of chronic tibial osteomyelitis: surgical technique and clinical results. J Orthop Surg Res. 2019;14.

10. Lowenberg DW, Buntic RF, Buncke GM, Parrett BM. Long-Term Results and Costs of Muscle Flap Coverage With Ilizarov Bone Transport in Lower Limb Salvage. J Orthop Trauma. 2013;27(10):576581.

11. Dahl MT, Gulli B, Berg T. Complications of limb lengthening. A learning curve. Clin Orthop Relat Res. 1994;(301):10-18.

12. Chim H, Sontich JK, Kaufman BR. Free Tissue Transfer with Distraction Osteogenesis Is Effective for Limb Salvage of the Infected Traumatized Lower Extremity. Plastic and Reconstructive Surgery.. 2011;127(6):2364-2372.

13. Shu H, Ma B, Kan S, Wang H, Shao H, Watson JT. Treatment of posttraumatic equinus deformity and concomitant soft tissue defects of the heel. J Trauma. 2011;71(6):1699-1704.

14. Park S, Lee TJ. Strategic considerations on the configuration of free flaps and their vascular pedicles combined with llizarov distraction in the lower extremity. Plastic and Reconstructive Surgery. 2000;105(5):1680-1686.

15. Ullmann $Y$, Fodor $L$, Ramon $Y$, Soudry $M$, Lerner A. The revised "reconstructive ladder" and its applications for high-energy injuries to the extremities. Ann Plast Surg. 2006;56(4):401-405.

16. Nho SJ, Helfet DL, Rozbruch SR. Temporary intentional leg shortening and deformation to facilitate wound closure using the llizarov/Taylor Spatial frame. J Orthop Trauma. 2006; 20(6):419-424.

17. Mckee MD, Yoo DJ, Zdero R, et al. Combined single-stage osseous and soft tissue reconstruction of the tibia with the llizarov method and tissue transfer. J Orthop Trauma. 2008;22(3):183-189.

\section{Tables}

Due to technical limitations, the tables are only available as a download in the supplemental files section. 


\section{Figures}
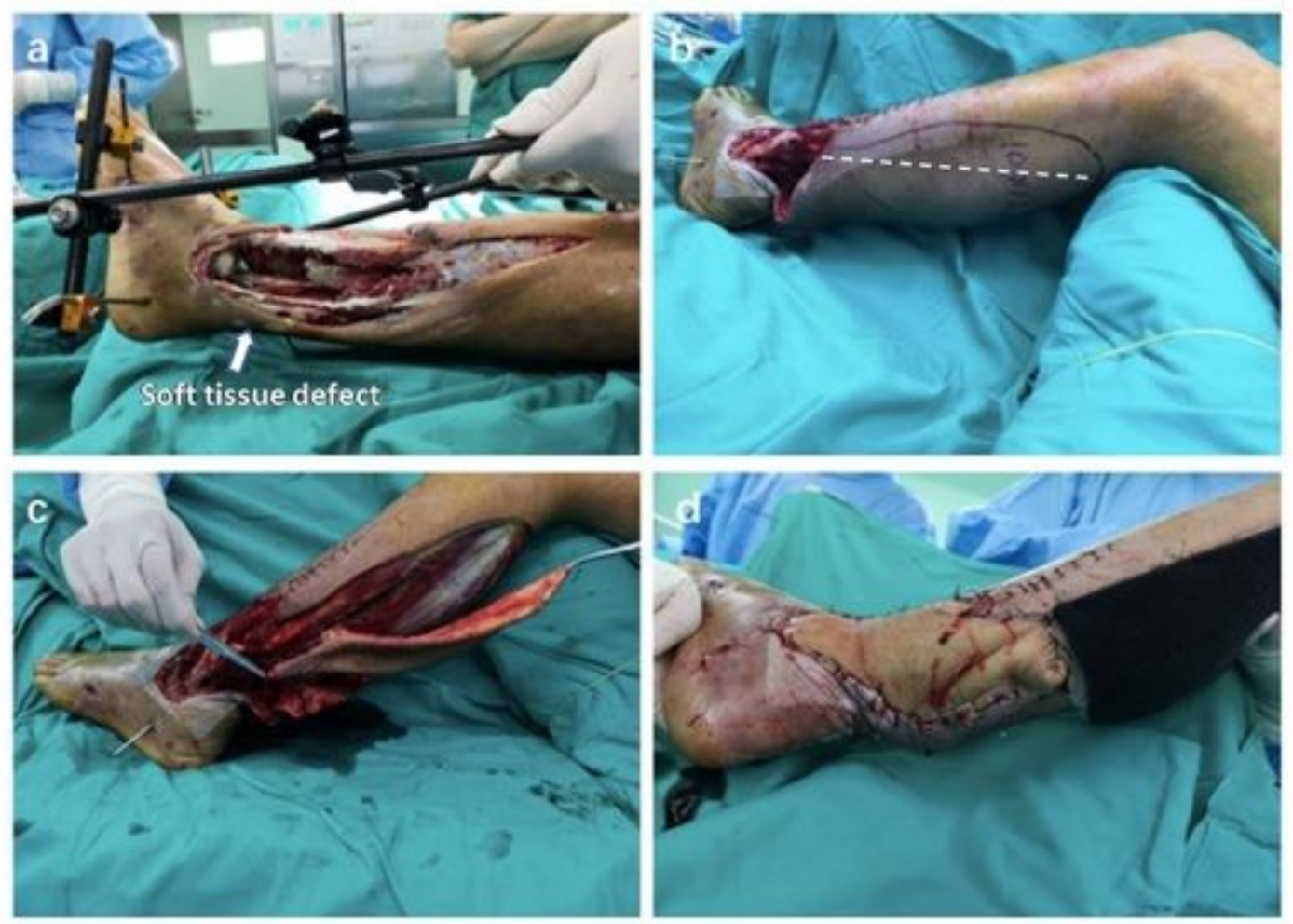

\section{Figure 1}

Patient 2. a, A temporary external fixator was applied. The soft tissue defect $(10 \times 12 \mathrm{~cm} 2)$ and bone loss $(5 \mathrm{~cm})$ can be seen. b, The great saphenous neurocutaneous flap $(10 \times 12 \mathrm{~cm})$ was designed. $c$, $d$, The flap was transferred to cover the soft tissue defect.
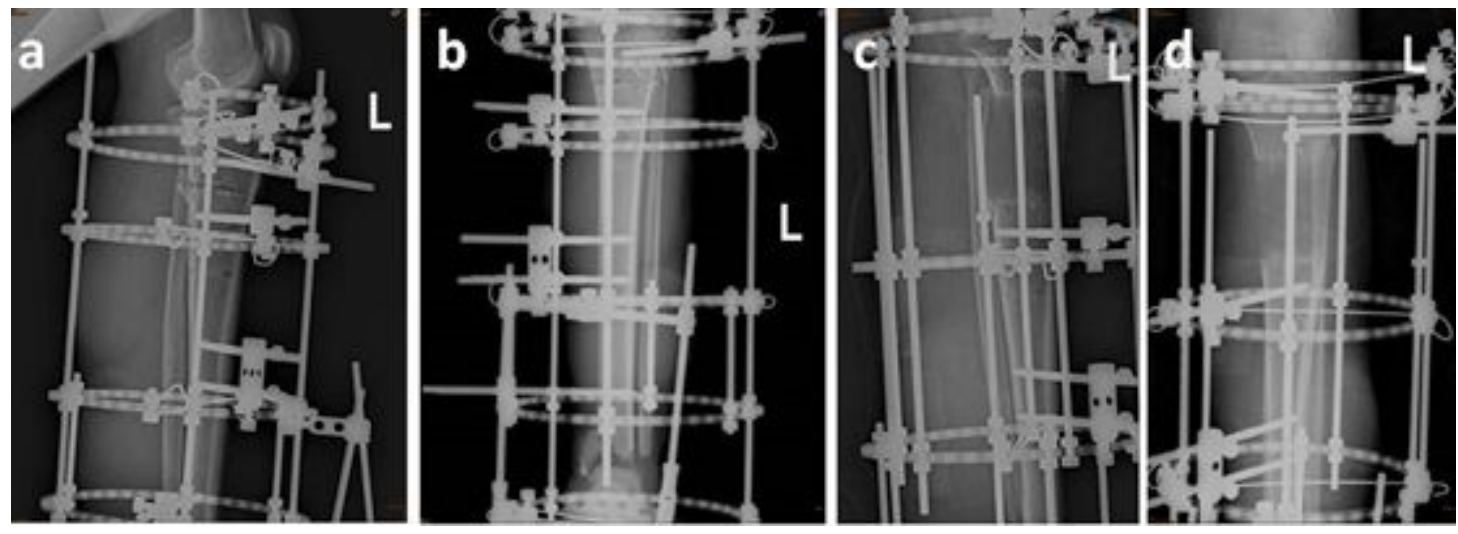

Figure 2

Patient 2. a,b, Dead bone $(5 \mathrm{~cm})$ was resected and acute shortening was performed after assembling the Ilizarov circular external fixator. c,d, New bone $(8.5 \mathrm{~cm})$ formed after distraction osteogenesis. 


\section{Supplementary Files}

This is a list of supplementary files associated with this preprint. Click to download.

- Table1.png

- Table2.png

- Table3.png 